\title{
Manuel Rodríguez y el húsar en el cine: un discurso histórico sin historiadores
}

\author{
Tomás Cornejo Cancino $\left.{ }^{*}\right)$
}

\begin{abstract}
RESUMEN
La figura de Manuel Rodríguez brilló como pocas durante los primeros años de producción fílmica chilena. Además de la recordada El húsar de la muerte (1925), en 1910 y 1920 se rodaron dos versiones sobre su actuación en la guerra de independencia. Se examina al respecto el modo en que los contemporáneos otorgaron validez histórica a tales películas, centrando su atención en los aspectos materiales llevados a la pantalla. La segunda parte del texto analiza el citado largometraje como una "visión fílmica de la historia", cuyo impacto supera al discurso historiográfico tradicional, cuestionando el relato explicativo realizado por los historiadores. El húsar de la muerte interpreta la gesta independentista como una guerra a muerte entre pobres y ricos, llevando a la pantalla una reflexión sobre un capítulo y un personaje clave de nuestra historia que fue validada socialmente. Cobran relieve los mecanismos cinematográficos utilizados por Pedro Sienna para dar forma a su película, enmarcados en un tipo de producción cultural característico de las primeras décadas de actividad fílmica, para explicar su articulación con otras manifestaciones discursivas que tuvieron al líder guerrillero como protagonista.
\end{abstract}

Palabras clave:

Manuel Rodríguez - cine silente - El húsar de la muerte - cine histórico.

${ }^{*}$ ) Doctor en Historia, El Colegio de México. Académico e investigador, Escuela de Historia, Facultad de Ciencias Sociales e Historia, Universidad Diego Portales, Santiago de Chile. 


\begin{abstract}
Manuel Rodríguez was a key figure during the first years of Chilean cinema. Besides the well-known El húsar de la muerte (1925), two other films about Rodríguez's intervention during the independence war were shot in 1910 and 1920. The article explores how the Chilean society of the time accorded these movies to have historical value, centering it attention on objects and decoration put on the screen. The second part of the article analyses the same motion picture as a "filmic vision of history", with a scope far beyond the traditional historiographical discourse. El húsar de la muerte explains the independence struggle as a cruel war between the poor and the riches, taking to the big screen an inquiry about a relevant chapter and character of our history that received social acceptance. The use of filmic resources made by director Pedro Sienna are relevant, as they were related with cultural production that characterizes the first decades of cinema, explaining its relationship with others discourses focused on the 'guerrillero' leader.
\end{abstract}

Keywords:

Manuel Rodríguez - silent film - El húsar de la muerte - historical cinema.

\title{
I. El pasado en la pantalla: certificación académica, cultura masiva y materialidad
}

Manuel Rodríguez fue protagonista indiscutido de nuestro cine silente. En quince años se rodaron tres films sobre él, siendo el más recordado El húsar de la muerte, dirigido y estelarizado en 1925 por Pedro Sienna. El mismo Sienna ya había interpretado al personaje cinco años antes, en Manuel Rodríguez, bajo la dirección de Arturo Mario. Y en 1910 se filmó la que es considerada la primera película argumental hecha en el país, llamada también Manuel Rodríguez, realizada por Luis Urzúa Rosas, quien dirigió a un grupo de aficionados. Ésta fue anunciada como "la grandiosa vista nacional, reconstrucción de los episodios del ilustre prócer de la independencia: Manuel Rodríguez, en 9 hermosos cuadros ${ }^{\prime \prime}$, uno de los cuales restauró y editó recientemente la Cineteca Nacional ${ }^{2}$.

La popularidad del líder insurgente a fines del siglo XIX y comienzos del XX era enorme. Cuando el cine daba sus primeros pasos, sus hazañas fueron un material ineludible para ser llevadas al celuloide. Era un personaje querido y querible, como lo prueban las reacciones de la audiencia frente a la película de 1910. "De que el público se manifestó satisfecho de la reconstrucción de las escenas que ponen de manifiesto la audacia y la agudeza del ingenio del guerrillero de la independencia", indicó un matutino, "lo demostró la salva de aplausos que estalló al final"3.

"La vida del héroe es sabida de memoria por todos los chilenos", anotó La Nación respecto al film rodado en 1920. Sobre su realización, el periódico resaltó que

\footnotetext{
${ }^{1}$ El Mercurio, 10 de septiembre de 1910, p. 5.

${ }^{2}$ Cineteca Nacional, Imágenes del centenario 1903-1933, DVD Documentos históricos II, 2010.

${ }^{3}$ El Mercurio, 11 de septiembre de 1910, p. 9.
} 
"exigía la más perfecta autenticidad histórica, ya que es por todos nosotros sabida la existencia de Manuel Rodríguez en nuestro primer acto de independencia" ${ }^{\prime 4}$. El paso de Rodríguez por las pantallas completó el ciclo de experiencias simbólicas tejido en torno a su memoria histórica, añadiendo el avance tecnológico más reciente a un repertorio cultural que incluía teatro, narrativa, poesía -popular y de elite- y, por supuesto, historiografía ${ }^{5}$. Las películas silentes se nutrieron de todas esas fuentes, pero, al añadir un nuevo lenguaje visual al conjunto, articularon una forma distinta de representarlo. Lo que más valoró la sociedad de entonces no fue la novedad del tema ni del personaje de Rodríguez, sino la correcta adecuación de tales elementos a un medio novedoso como el cine ${ }^{6}$.

Frente a este cúmulo de expresiones literarias y teatrales, entre las que sobresale Durante la Reconquista, exitosa novela de Alberto Blest Gana publicada en 1897, la historiografía fue reticente. Atrapada por los muros de un cientificismo austero, por una parte, y dedicada a la consagración de las figuras oficiales, por otra, la Historia proveniente de la academia no fue muy devota de Rodríguez. Lo trató con parquedad, contrastando con el culto que suscitaba entre las clases populares7. "La historia patria, aunque relata en forma más o menos extensa las hazañas del ilustre guerrillero -se quejó El Diario Ilustrado- deja en el vacío hechos y anécdotas que constituyen la base de la popularidad de Manuel Rodríguez y que nuestro pueblo las sabe de memoria"8. Este tipo de reproches dirigidos a la historiografía ilustran la demanda por la figura de Rodríguez que el cine estaba en condiciones de satisfacer.

Las adaptaciones fílmicas debían ceñirse a un guión histórico que, "bien sabido por todos", era un guión social. Sus reinterpretaciones añadían algo, fueran nuevos personajes o circunstancias. O bien, omitían algún elemento, prefiriendo acentuar determinados rasgos del protagonista. Sobre el Manuel Rodríguez de 1910, la prensa comentó que "como primer ensayo de esta forma de popularizar la historia patria, el éxito es bueno", aun cuando algunos detalles de vestuario y de las armas denotaban ciertos anacronismos ${ }^{9}$.

El estreno del Manuel Rodríguez dirigido por Arturo Mario se verificó en Valparaíso el 18 de mayo de 1920 y pocos días después en Santiago. Luego de una semana en las salas capitalinas, la cinta seguía exhibiéndose en tres teatros y en horario doble, algo inusitado para la época. De acuerdo a Eliana Jara, este éxito de público llevó a que el film siguiera proyectándose los años venideros con similar acogida de audiencia ${ }^{10}$. La prensa fue unánime en alabar los aspectos técnicos de la cinta, cuyo director, de

\footnotetext{
${ }^{4}$ La Nación, 2 de junio de 1920, p. 9 y 9 de mayo de 1920, p. 11.

${ }^{5}$ Al respecto, Guajardo, Ernesto, Manuel Rodríguez. Historia y leyenda, Ril editores, Santiago, 2010.

${ }^{6}$ Un antecedente temprano de la popularidad de Rodríguez puede fecharse en 1824. Ese año se presentó una "comedia de magia", espectáculo que combinaba teatro con efectos ópticos, donde se ensalzaba su figura como salvador del país, provocando ovación entre los asistentes a la función e inquietud entre las autoridades. Maturana, Carmen Luz, "La Comedia de Magia y los efectos visuales de la era pre-cinematográfica en el siglo XIX en Chile", en Aisthesis, N45, 2009 , p.85. ${ }^{7}$ Guajardo, Ernesto, Op. cit., p. 27.

${ }^{8}$ El Diario Ilustrado, 16 de noviembre de 1925, p. 10

${ }^{9}$ El Mercurio, 10 de septiembre de 1910, p. 5. Es poco lo que se sabe respecto a este primer film, aparte de que tuvo buena recepción de la prensa y del público, y que fue preparado en apenas tres meses. Cf. "Cinematografía chilena", en Cine Gaceta, primera quincena de octubre de 1915, pp. 8-9.

${ }^{10}$ Jara Donoso, Eliana, Cine mudo chileno, Fondart, Santiago, 1994, p. 26.
} 
origen argentino, tenía amplia experiencia en el teatro y el cine ${ }^{11}$.

El guión era una adaptación del dramaturgo Rafael Raveau de la citada novela de Blest Gana. Junto con felicitar a los realizadores por exponer en pantalla "temas genuinamente nacionales", los comentarios periodísticos destacaron la veracidad de la película: "Esta cinta ha sido confeccionada con los documentos históricos más auténticos de la vida del héroe y para ello se ha recurrido a las más valiosas fuentes de información", según La Nación.Para confeccionar los vestuarios "se ha valido la dirección artística de la cinta de los diseños que aparecen en el Álbum Geográfico de Chile del ilustre sabio francés Don Claudio Gay, que se encuentra en la Biblioteca Nacional"12.

La pantalla grande comenzaba así a exhibir sus potencialidades como aliada de la instrucción masiva y de la transmisión de la historia, en el contexto de un nacionalismo cultural con nuevos bríos ${ }^{13}$. A la fecha, el cine ya se había instalado en el país como una actividad de consumo cultural masivo. Estaba en discusión su estatuto de manifestación artística, que en Europa estuvo determinado por su nacimiento, más cercano al espectáculo popular que al refinamiento académico o al buen tono. Aquí y allá, las disquisiciones estéticas sobre la imagen en movimiento se realizaron a la par de las reflexiones sobre sus usos científicos y su utilización social, enfrentando visiones que esperaban que el cinematógrafo fuera un eficaz "agente moralizador", al ampliar la cobertura de los mensajes de la ideología oficial y alejar de los "vicios" a las clases obreras, contra aquellos que pensaban que las películas sólo "pervertían" y enseñaban "costumbres ajenas"14.

Con respecto a la representación del pasado en la pantalla, los comentarios de la época indican que se conceptuaba al cine como un instrumento eficaz, lo que explica su utilización en las filmografías de prácticamente todos los países ${ }^{15}$. La capacidad figurativa del lenguaje fílmico permitía adentrarse en el pasado. La gesta de la emancipación podía ser recuperada de la mano de los próceres que figuraban en el Manuel Rodríguez de 1920, "y con ellos conoceremos el ambiente de la época en que actuaron con sus asonadas, tipos populares, usos y costumbres, vestuarios, elementos de guerra, etc., y todo reproducido con una autenticidad que da la ilusión perfecta de lo real"16(fig. 1).

\footnotetext{
${ }^{11}$ La Nación, 2 de junio de 1920, p. 9.

${ }^{12}$ La Nación, 8 de mayo de 1920, p.16 y 16 de mayo de 1920, p. 11.

${ }^{13}$ Subercaseaux, Bernardo, Historia de las ideas y de la cultura en Chile, Tomo IV: Nacionalismo y cultura, Editorial Universitaria, Santiago, 2007, pp. 169-244.

${ }^{14}$ Sobre estos problemas, Bongers, Wolfgang, "El cine y su llegada a Chile: conceptos y discursos", en Taller de letras, $\mathrm{N}^{\circ}$ 46, 2010, pp. 151-174; Iturriaga, Jorge, "Rentabilidad y aceptación. La imagen de Chile en el cine argumental, 1910-1920", en Cátedra de Artes, N², 2006, pp. 67-87.

${ }^{15}$ Kracauer, Siegfrid, De Caligari a Hitler. Una historia psicológica del cine alemán, Paidós, Barcelona, 1995 [1947]; Miquel, Ángel (coord.), La ficción de la historia. El siglo XIX en el cine mexicano, Cineteca Nacional, México D.F., 2010; Bordwell, David, El cine de Eisenstein. Teoría y práctica, Paidós, Barcelona, 1999; Laborda, Luis, La historia en el cine norteamericano. La ficción cinematográfica como (re)creación e interpretación del pasado, Editorial Milenio, Lleida, 2010.

${ }^{16}$ La Nación, 19 de mayo de 1920, p. 11.
} 


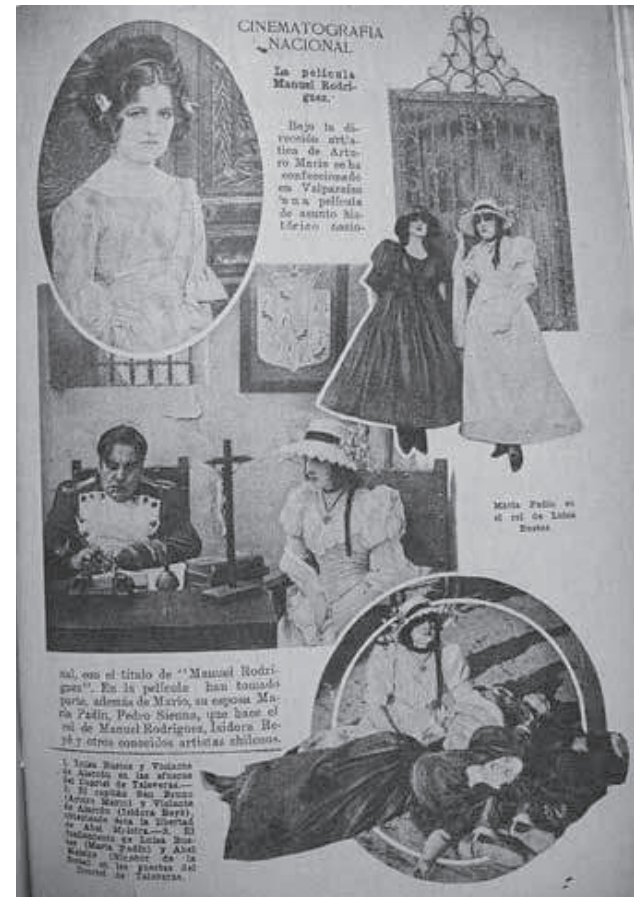

Fig. 1: Zig-Zag, 15/05/1920, p. 42.

Pero en el caso de un film histórico, ¿cómo asegurarse de que el efecto mimético se lograra a cabalidad? Según lo reseñado por la prensa, la visualidad del pasado se cimentaba en elementos materiales. "Los trajes de los civiles son de excelente presentación" en la cinta de 1920, tanto así que "dan al espectador la sensación de la realidad. La indumentaria del elemento militar está de acuerdo con la época, lo mismo el armamento [...]"17. Los realizadores habían tenido que "reconstruir una época íntegra de la historia patria", lo que suponía un reto dado "lo incipiente que es nuestro arte de la pantalla". Pero se había salvado con éxito "con una dirección consciente y la supervigilancia, que han tenido numerosos intelectuales chilenos en la confección de la obra"18.

La presencia de historiadores e "intelectuales" -cuyos nombres se ignoran-, era lo que socialmente, para el Chile de 1920, confería veracidad histórica al trabajo fílmico. El saber historiográfico sobre el pasado fue una autoridad desplazable del conocimiento cerrado de los libros ${ }^{19}$, a la proyección del fenómeno cinematográfico. Claudio Gay y "numerosos documentos" de por medio, se esperaba vivenciar en la pantalla los años de la Independencia. La adaptación temporal se jugaba por entero en lo que hoy se denomina dirección artística. Trajes, objetos, arquitectura y aun el que "las escenas se desarrollan en los mismos lugares en que la historia nos cuenta haber sucedido" ${ }^{\prime 20}$, eran

\footnotetext{
${ }^{17}$ La Nación, 2 de junio de 1920, p. 9.

${ }^{18}$ Ibíd. El mismo periódico informó días antes: “Todo el material y cimientos empleados en esta obra, han sido revisados por una comisión de historia, a fin de que no escapara un solo detalle que no marchara, en armonía con la autenticidad [...]. Para la ejecución de San Bruno hubo de reconstruirse la Catedral de Santiago, de aquella época, trabajo que se encomendó a un arquitecto nacional". La Nación, 20 de mayo de 1920, p. 9.

${ }^{19}$ Woll, Allen, A Functional Past. The Uses of History in Nineteenth-Century Chile, Louisiana State University Press, Baton Rouge and London, 1982, p. 157.

${ }^{20}$ La Nación, 2 de junio de 1920, p. 9.
} 
garantía de historicidad. Al momento de referirse a la historia, ésta parece signada sólo por su alteridad material. Y en ese ámbito, pareciera que los historiadores tenían reservado el papel de anticuarios.

Cuando se estrenó El húsar de la muerte el debate también se enfocó en la acertada reconstrucción histórica, entendiendo ésta como el mecanismo más adecuado para conocer el período inmediato a 1810. Las escenas del film daban la "impresión agradable de estar viviendo esa época de hazañas y glorias donde se siente transportado por el encanto y perfección tanto de la trama como de la correcta interpretación [...]; habríamos deseado seguir mucho tiempo arrobados por ese período tan fielmente representado y tan correctamente ideado" -indicó un comentarista- ${ }^{21}$. La ilusión continuaba asentándose en la materialidad, por lo que era plausible que la mimesis de lo real que entregaba la imagen en movimiento se extendiera hacia atrás en el tiempo: "Cada actor fue cuidadosamente elegido para que hasta su físico correspondiera exactamente al personaje histórico que decía encarnar. Se buscaron con tesón armas, utensilios y trajes de la época, preparándose lo que faltaba sin reparar en gastos" ${ }^{\prime 22}$.

Si bien lo que prima en estas consideraciones es lograr una representación imitativa de la realidad a través de su duplicación física, queda la pregunta de para quiénes pudo efectivamente haber coincidido lo que se proyectaba en la sala de cine con las evidencias documentales del período. Es decir, ¿para cuántas personas un arma, utensilio o traje determinado era identificable con los de principios del siglo XIX? ¿Quiénes podrían efectivamente dar fe del parecido de los actores con los personajes que representaban?

Dos instancias fundamentales de la primera mitad de siglo $\mathrm{XX}$, la prensa y el cine, configuraron en conjunto una representación social del pasado que escapó finalmente del control de los historiadore ${ }^{23}$. Su autoridad intelectual fue expropiada por un circuito cultural más abierto, en tanto la imagen en su elocuente evidencia convence con sólo mirar. El mero hecho de insertar un atuendo o un objeto determinado en la trama de El húsar le confería la patente de histórico. Y el aval lo daba la prensa, alabando las reconstrucciones o criticando los anacronismos demasiado evidentes. Entonces como hoy, diarios y revistas eran los voceros de los realizadores cinematográficos, promocionando las bondades de cada producción. La verdadera crítica especializada se desarrolló con posterioridad en Chile, lo que no obsta para considerar a la prensa de las primeras décadas del XX como un espacio de intermediación entre el cine y el público, capacitado para aprobar o desdeñar los cometidos de aquél en tanto forma de entretención o expresión cultural "seria"24.

El visto bueno respecto al cine histórico quedó en manos de publicistas, reporteros y comentaristas. Puesto en imágenes, el pasado de las cintas que tuvieron a Manuel

\footnotetext{
${ }^{21}$ La Nación, 25 de noviembre de 1925, p. 11.

${ }^{22}$ La Nación, 19 de noviembre de 1925, p. 11

${ }^{23}$ Para otras experiencias en América Latina, ver: Raxon, Philippe, "San Martín: un Libertador à l'affiche", Joset, Jacques (ed.), Littérature, histoire et cinéma de 1' Amerique hispanique, Actes du Colloque du Centre de Recherches et d'Études sur l'Amerique Ibérique, Université de Liège, Liège, 2003, pp. 137-161 y Tuñón, Julia, "Juárez y Maximiliano: dos caras de una moneda en el imaginario fílmico del cine clásico mexicano", Vázquez, Josefina Zoraida (coord.), Juárez: historia y mito, El Colegio de México, México D.F., 2010, pp. 113-137.

${ }^{24}$ Mouesca, Jacqueline, El cine en Chile: crónica en tres tiempos, Planeta - Universidad Andrés Bello, Santiago, 1997 y Bongers, Wolfgang. Op. cit.
} 
Rodríguez como atractivo se erigió en una versión de la historia más al alcance del público masivo y alejado de la academia, haciendo eco a una demanda de conocimiento social del pasado que había encontrado respuesta con el circuito cada vez más numeroso de lectores de historiografía de divulgación, bajo la forma de historia novelada o novela histórica.

La versión cinematográfica más acabada de las aventuras de Manuel Rodríguez, que lo elevan como el máximo exponente de la gesta independentista, constituyen una verdadera "visión fílmica de la historia". Con los recursos propios del lenguaje visual y con un impacto que supera con mucho al discurso historiográfico comunicado por escrito, aquél pone en tela de juicio el relato explicativo realizado por los historiadores. Sin pretensiones de veracidad, es una elaboración sobre el devenir que merece ser examinada, en tanto es una reflexión sobre el pasado que remite también al presente en que es producida ${ }^{25}$.

\section{El húsar de la muerte y la otra versión de lo histórico}

Estrenado en Santiago el 24 de noviembre de 1925, El húsar de la muerte logró un éxito de público inmediato (fig. 2). Pedro Sienna se repitió en el papel protagónico, asumió también la dirección y fue el co-guionista junto a Hugo Silva. Los periódicos se congratularon por lo que -una vez más- parecía ser el despegue de la filmografía local. Por su potencial económico, además del "contenido patriótico" de películas de este tipo, clamaban por el apoyo del gobierno para que aquellas se multiplicaran.

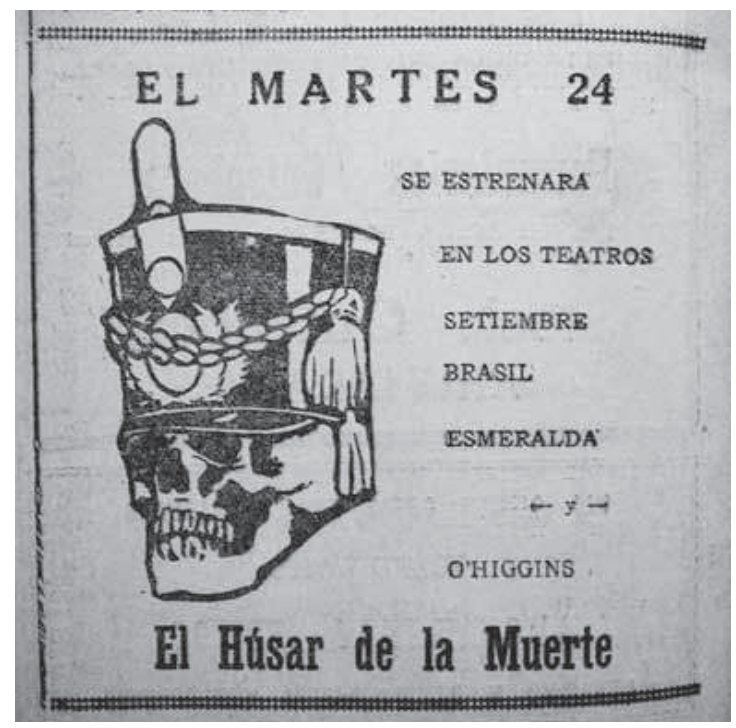

Fig. 2: El Diario Ilustrado, 16/11/1925, p. 10.

Buena parte del éxito y la acogida favorable de El húsar se debe a su conexión con los gustos de los espectadores, por el tema, pero también por el género cinematográfico en que se inscribe: el melodrama. La cinta de Sienna es, en efecto, un melodrama de

\footnotetext{
${ }^{25}$ Rosenstone, Robert, El pasado en imágenes. El desafío del cine a nuestra idea de la historia, Ariel, Barcelona, 1997, pp. 27-42. Del mismo autor, History on Film/ Film on History, Pearson Longman, Great Britain, 2006, pp. 11 y ss.
} 
ambientación histórica que incluye todas las claves y tópicos necesarios: el héroe, el villano, la amada, los amigos del héroe y un sinnúmero de peripecias por las que atraviesan; comparte una forma de entender la narración fílmica característica del período silente. Película de aventuras de fácil decodificación, la obra es también muy buena considerada desde el lenguaje fílmico. Sienna despliega todos los recursos que permiten establecer un relato efectivo desde la imagen. Su película es un pequeño compendio de cuán complejo llegó a ser el cine mudo en términos expresivos y narrativos ${ }^{26}$.

Al respecto, Alicia Vega apuntó que Sienna "aborda la recreación histórica [...] con entera libertad y falta de convencionalismos" ${ }^{27}$. Me interesan sobre todo los desplazamientos de sentido que realiza el film, las reinterpretaciones del período histórico de la Independencia y de los personajes involucrados que vehiculan sus imágenes. Aquí, alteraciones, adiciones, ausencias u omisiones respecto a las versiones historiográficas de los hechos en cuestión, a un siglo de sucedidos, son indicativas de problemas vigentes cuando se filmó El húsar, así como de otras propuestas para significar y relatar qué sucedió en el pasado que recrea.

\section{Desplazamientos}

Lo que más me llama la atención de la cinta es su forma de conceptuar a patriotas y españoles como "buenos" y "malos". Se muestra la emancipación política como una necesidad dado el dominio opresivo y violento de la represión hispana. Se ve cómo los soldados queman los ranchos de los campesinos, violan a sus mujeres y fusilan a sus camaradas. Eso justifica la rapidez con que Rodríguez convence a peones e inquilinos de que abandonen el trabajo y se unan a la insurgencia.

Establecidos ambos campos en disputa, sin embargo, la cinta los presenta con caracteres particulares. Los realistas son también ricos. En cambio, los patriotas son a su vez pobres. Desde la primera escena se enseña cuáles son los espacios propios del bando realista: una casa de la elite, la residencia del gobernador, lugares de reunión social. Tales escenarios buscan aparecer con elegancia y boato. Los personajes que se mueven en ellos están caracterizados en el mismo tono, con trajes finos, vestidos y pelos ornamentados. "Nuestras abuelas con sus pelucas empolvadas [...], nuestros abuelos con sus trajes de Luis $\mathrm{XV}^{\text {", }}$, según un matutino identificado con aquello ${ }^{28}$. Movimientos y actitudes corporales completan el cuadro, se trata de la alta sociedad, de los ricos que nadan en la abundancia.

Las montoneras patriotas, por el contrario, habitan un espacio precario. Su refugio es un rancho campesino, casi sin amoblar. Exceptuando al protagonista, los partidarios de éste y la familia que les brinda acogida son caracterizados como gente del pueblo. Se visten con lo justo, están mal armados y tienen dificultades para alimentarse, pese a lo cual entre ellos reina la camaradería, la solidaridad y la risa. El contraste entre ricos y pobres es evidente, como también lo es la postura moral implicada. Los buenos de la película son los pobres. Los malos son los ricos, que tienen asimismo su expresión

\footnotetext{
${ }^{26}$ Ruffinelli, Jorge, "La aventura y la patria: El húsar de la muerte (1925) de Pedro Sienna”, en Aisthesis, N 37, 2004, pp. $45-63$.

${ }^{27}$ Vega, Alicia, et al. Re-visión del cine chileno, Editorial Aconcagua - Céneca, Santiago, 1979, p. 53.

${ }^{28}$ El Mercurio, 8 de noviembre de 1925, p. 32.
} 
armada, que se escenifica en los cuarteles militares. La oposición binaria también se manifiesta en términos de la dualidad campo-ciudad. El ámbito rural, sea el mundo agrícola o los caminos abiertos por los que corren los fugitivos patriotas, se opone al espacio citadino, de la urbanidad refinada y de los salones cerrados de los realistas.

Resumiendo, la película dirigida por Sienna representa la lucha independentista como una guerra entre ricos y pobres, en una lectura de la historia inédita para su época. Desde la historiografía académica las interpretaciones han ido por otros derroteros. En general, lo que se argumenta actualmente es que la coyuntura abierta en 1810 fue un conflicto intra-elitario con caracteres de enfrentamiento civil. Sin embargo, la participación de los sectores populares, y en particular del "bajo pueblo", está siendo re-evaluada por los historiadores. Sus preguntas buscan desentrañar si las clases subordinadas fueron algo más que simple tropa movilizada a la fuerza por sus patrones, carne de cañón obligada de un enfrentamiento ajeno. Porque -se argumenta- tal vez sí generaron una conciencia de las implicaciones de esa lucha, aunque desde una perspectiva distinta. El propio film pareciera insinuar algo en una escena donde Rodríguez encara a un soldado en la puerta del cuartel realista y lo convence de pasarse al otro bando. "Yo te conozco, -le dice- tú eres Pancho Rojas, hijo del Viejo Rojas y de la Pancha de Rojas, un chileno como yo". La patria, de acuerdo con ello, se construiría con vínculos sociales horizontales en un universo donde el contacto personal y el reconocimiento serían posibles.

Pero en ningún caso la historiografía ha planteado entender la Independencia como un conflicto de clases de la forma en que se interpreta en El húsar de la muerte. Para cuando la película fue realizada, el sentido común histórico tendía a incluir sin más al "pueblo chileno" en el ala patriota, en tanto que la academia, desde los historiadores liberales en adelante, no consideraron a las clases populares como sujetos históricos. La historia de los grandes hechos era llevada a cabo por los grandes hombres ${ }^{29}$.

Hay dos explicaciones para que los realizadores hubieran concebido en estos términos el contenido del film. La primera apunta a la "zona de realidad no visible", según la sugerencia de Marc Ferro. Determinados "contenidos latentes" de la realidad social en la que está inmerso el equipo que realiza una película (y aquí el carácter colectivo del trabajo cinematográfico cobra peso) son incorporados a su producción fílmica ${ }^{30}$. Los elementos de la construcción dramática y sus manifestaciones simbólicas remiten así a la exterioridad de la obra, al contexto social y cultural. Los contenidos latentes se proyectan en aquella, introduciéndose subrepticiamente. Aunque otras veces también cumplen la función de metáfora. Algo de esto último se atisba en el film rodado por Sienna. Porque una lucha de clases de tales contornos parece retrotraer a la "cuestión social" de comienzos del siglo XX. Los enemigos del pueblo son enemigos de clase, en la década de 1920 y en el film, pero no en el pasado histórico que representa. Esta transferencia temporal es un anacronismo fantástico, un anacronismo social y político -alejado del control de la historiografía oficial-, que proyecta al pasado los problemas sin solución del presente.

\footnotetext{
${ }^{29}$ Al finalizar su monumental Historia General de Chile, Diego Barros Arana argumentó: "me he empeñado en dar a conocer por sus hechos a los hombres más notables, los únicos que merecen ser sometidos a este examen".

${ }^{30}$ Ferro, Marc, Historia contemporánea y cine [1977], Ariel, Barcelona, 2000, p. 39 y ss.
} 
Aunque no hay que exagerar, El húsar no es una proclama revolucionaria. Para comprender mejor su mensaje hay que contemplar las características del cine de aquellos años. La vinculación con la escena teatral plebeya fue común en las primeras décadas de actividad fílmica ${ }^{31}$. En América Latina, la zarzuela y el "género chico" teatral constituían un verdadero circuito cultural masivo en el que participaban las clases populares urbanas y los grupos sociales medios. Junto a las comedias, abundaban aquí obras que se estructuraban narrativamente como melodrama, provocando un compromiso afectivo del auditorio ${ }^{32}$. A medida que el cine se impuso, actores, libretistas y directores hicieron el tránsito de un medio al otro, llevando consigo el bagaje respecto a cómo construir una buena historia.

El tono narrativo del espectáculo teatral pasó entonces al mundo de la pantalla. Los espectadores esperaban ver una entretención, un espectáculo; los valores añadidos -enseñanzas morales, virtudes cívicas, recuerdos patrióticos, principios de higieneeran aceptados con los brazos abiertos, siempre y cuando se entregaran en términos fácilmente discernibles, bajo la forma de un relato donde el bien y el mal entraran en pugna encarnados en personajes representativos.

Las expectativas generadas en un público habituado y educado en el melodrama eran cruciales. "Hay, claro está, muchas concesiones al gusto de la galería -indicó un comentarista sobre la película en cuestión-, que delira de entusiasmo en ciertos pasajes; pero en resumen, deja la impresión de un argumento pensado con inteligencia y bien desarrollado" ${ }^{\prime 3}$. Ambos elementos, las concesiones y el argumento logrado dieron forma a El húsar, un relato de aventuras, una figura heroica, un idilio, todo bien presentado con un ritmo en el que se aprecian los buenos usos del montaje cinematográfico.

Pero si la cinta representa la coyuntura independentista como conflicto de clases, surge la pregunta por el personaje de Rodríguez, a quien se lo ve tanto en la ciudad como en el campo, recorriendo los caminos y cómodamente instalado en una hacienda. Su ubicuidad, según la película, es de orden espacial, aunque indica también movilidad social. La legendaria capacidad del personaje histórico de disfrazarse para ocultar su identidad, en la cinta es correctamente comunicada como cambios en su fisonomía y su indumentaria. Es notable, en tanto efecto visual, la escena en que los soldados realistas describen al capitán San Bruno los muchos rostros con que se ha visto al líder patriota. En la imagen mental que se construye el oficial, no es sólo la cara del fugitivo la que cambia, sino su identidad toda.

El protagonista de El húsar transforma su completo ser social. Se ríe, come y bebe como uno más entre los campesinos y peones de la montonera. Adopta luego los aires y maneras de un noble en un sarao; actúa como un caballero al defender su honor; es finalmente un alto oficial del ejército chileno. Tal ubicuidad, exagerada para explicitar los recursos del prócer, separa sin embargo al Manuel Rodríguez cinematográfico,

\footnotetext{
${ }^{31}$ Pérez Rubio, Pablo, El cine melodramático, Paidós, Barcelona, 2004, p. 23.

${ }^{32} \mathrm{Al}$ respecto, Martín-Barbero, Jesús, De los medios a las mediaciones. Comunicación, cultura y hegemonía, Convenio Andrés Bello, Bogotá, 5a ed., 2003, p. 151 y ss.

${ }^{33}$ Zig-Zag, 19 de diciembre de 1925.
} 
tanto de uno como del otro bando en disputa. Ni rico ni pobre, es sencillamente el héroe. Aunque pueda entregar la vida luchando por los oprimidos y estar codo a codo con los campesinos, no es uno de ellos. Porque él es "Don Manuel", como le remarcan al inicio del film a uno de sus guerrilleros, que no ha mostrado el respeto debido; y cuando "Don Manuel" llega al refugio patriota, todos se levantan en gesto de cortesía y lo atienden como se merece.

\section{Adiciones}

Otro aspecto de la película que me parece central es la inclusión de personajes ficticios junto a los personajes históricos, ejercicio que remite a ciertas intenciones expresivas en el conjunto de una obra. Sienna realiza aquello adelantándose décadas a los historiadores, cuando hace partícipes y protagonistas de la historia a los niños, grandes ausentes de las narrativas académicas. En lo que se me figura como una maravillosa intuición histórica de los realizadores, además, dan una importancia central a un niño que no es uno cualquiera: el Huacho Pelao.

Si algo distingue a la película dirigida por Sienna, es la presencia de un niño en medio de un pasado histórico, de acontecimientos que en 1925 eran una de las gestas fundantes de la memoria chilena. Y es una presencia fundamental para el relato, el contrapunto perfecto de las conocidas hazañas del protagonista. No así las del Huacho Pelao, pura ficción histórica que acierta desde la intuición para poner en pantalla los rasgos de un conjunto de sujetos marginados de las visiones oficiales sobre el pasado nacional.

Hay un segundo personaje ficticio relevante, aunque en otro sentido. Se trata de Carmen (interpretada por la actriz Clara Wherter), hija del Marqués de Aguirre, cuya función es ser catalizador de uno de los principales sentidos históricos propuestos por la cinta. Su sola presencia justifica el desarrollo de un idilio con Rodríguez. Esta inclusión hay que entenderla también en el contexto del cine silente, donde el amor romántico invadía las pantallas y era un factor en la cadena de producción melodramática.

La publicidad de El húsar hizo hincapié en ese aspecto: "La marquesa de Aguirre era de un carácter altivo, orgullosa hasta la exageración, altanera en sumo grado, con orgullo de nobleza rancia, y tuvo que doblegarse ante la espantosa realidad, el amor de su vida era hacia un plebeyo, y ese plebeyo era patriota" ${ }^{\prime 34}$. Plebeyo, sí, pero no un hombre del bajo pueblo, sino socialmente ubicuo, conocedor de los códigos así de la cortesía como del cortejo de la alta sociedad. Y Carmen, por su parte, es en efecto de cuna noble. Es, además y por sobre todo, adicta a la causa realista. Frecuenta al gobernador Marcó del Pont y al capitán San Bruno, el encargado de capturar a Manuel Rodríguez.

\footnotetext{
${ }^{34}$ La Nación, 14 de noviembre de 1925, p. 11.
} 
Con este último, entonces, Carmen pareciera tener más diferencias políticas que sociales. Pero un par de miradas a la entrada de la iglesia bastan para que quede prendada del apuesto joven que le alcanza con galantería el pañuelo. Y por supuesto ella no sabe que ese desconocido es el líder de la resistencia patriota. Y él a su turno ignora que la hermosa doncella de la cual se ha enamorado, ha jurado que gustosa daría muerte al líder de los rebeldes, un insolente que turba el orden establecido.

Toda esta línea argumental, sin embargo, no tiene siquiera un desenlace. Luego de un par de escenas de remanso idílico, la cinta retorna a la lógica de los hechos políticos e históricos. El amor queda así supeditado a algo que parece ser más importante, la guerra, la Independencia, la gesta patriótica. Hay, con todo, un sentido específico de la presencia del personaje de Carmen. En el conjunto de la producción simbólica referida a Manuel Rodríguez, el film de Sienna no es el único que recurre al amor. En el caso de El húsar, la función narrativa de lo amoroso implica una reinterpretación mayor del conflicto real en el cual se enmarca. El romance entre el patriota y la realista insinúa que el antagonismo político puede disolverse. Los realizadores del film, deliberadamente o no, sugieren aquí otra interpretación de la Independencia. La guerra fratricida encuentra, por medio del amor, una forma de resolución pacífica aunque sea momentánea. El amor puede lo que no logra la razón ni la fuerza. Incluso la casona de Carmen, una gran propiedad suburbana, media entre los espacios identificados con los bandos en disputa.

Ese tópico no es inédito dentro de la imaginación histórica chilena. Elizabeth Lira y Brian Loveman han visto en su presencia, y en lo recurrente de ese mecanismo de resolución de conflictos sociopolíticos, una "vía de reconciliación" que se mantiene hasta nuestra reciente post-dictadura ${ }^{35}$. La metáfora de la "gran familia chilena" eventualmente dividida, pero que logra escamotear los conflictos sin resolverlos, es clave para entender los llamados a la conciliación, la unidad y el consenso, de los años que siguen a un período traumático. $\mathrm{Y}$ es algo que surge en los procesos históricos, tanto como en las manifestaciones culturales que toman dichos procesos como materia prima a representar ${ }^{36}$.

Esto vuelve mucho más complejo el contenido del film. La inicial extrapolación del enfrentamiento político en términos clasistas pierde fuerza, induciendo una lectura matizada. Una versión del pasado en esos términos no era en absoluto descabellada. Ya en 1920, con el film donde Sienna interpretó por primera vez el personaje de Rodríguez, la recepción social de la película fue sensible a esta interpretación histórica. En un tono a su vez muy conciliatorio, La Nación comentó: "al mismo tiempo que enaltece el sacrificio de los patriotas, pone de relieve el valor y la lealtad de los valerosos ejércitos realistas [...] la causa que ellos y nosotros defendíamos era noble y elevada. La cinta Manuel Rodríguez deja constancia de ambas y denota en su autor un espíritu moderno de justicia y equidad" ${ }^{\prime 37}$.

\footnotetext{
${ }^{35}$ Loveman, Brian y Elizabeth Lira, Las suaves cenizas del olvido. Vía chilena de reconciliación política 1814-1932, LomDibam, Santiago, 1999.

${ }^{36}$ Al respecto, Hunt, Lynn, The Family Romance of the French Revolution, Berkeley, University of California, 1992; y en especial Sommer, Doris, Ficciones fundacionales: las novelas nacionales de América Latina, Bogotá, F.C.E., 2004 [1993].

${ }^{37}$ La Nación, 29 de mayo de 1920, p. 9.
} 


\section{Ausencias}

Un país conciliado es un país feliz. Y ese podría ser el final de la historia, pero sabemos bien que no lo es, tal como los espectadores de comienzos del siglo $\mathrm{XX}$, porque el Manuel Rodríguez real tuvo un final violento y trágico. Esto recuerda que en el relato efectuado por El húsar de la muerte hay una ausencia significativa. Bernardo O'Higgins casi no existe en su universo diegético. Prácticamente ni figura, apenas se lo nombra en un título al comienzo y en otro al final. Este último no corresponde a los cartones originales del film y posiblemente haya sido intercalado por Sergio Bravo al restaurarlo en la década del 60.

Lo importante es que $\mathrm{O}^{\prime}$ Higgins desaparece, se le niega algún protagonismo histórico. En la preparación del Ejército Libertador, sólo José de San Martín es importante. Los viajes de Rodríguez a Mendoza son para reunirse con el general cuyano. Lo mismo cabe decir después que las tropas patriotas cruzan hacia Chile y vencen a los españoles. Si en primera instancia pudiera pensarse que hay una intención de relegar a O’Higgins, al mismísimo Libertador a un segundo plano, minimizando su relevancia, de forma tal que el film presentaría una versión alternativa del pasado, creo que no es tan así. Al contrario, la ausencia de O’Higgins apunta en el mismo sentido conciliador antes reseñado. Porque la decisión de que no figure en la narración permite a los realizadores no aventurarse en el pantanoso terreno de la muerte de Manuel Rodríguez ordenada por el Director Supremo.

Incluso algunos comentaristas de prensa que alabaron la película, criticaron negativamente el hecho que el final fuera tan abrupto. Una escena da cuenta del asesinato artero de Rodríguez y del inicio del culto popular a su figura, pero no se muestra ni se insinúa quién dio las órdenes de matarlo. Se exculpa así a O’Higgins, evitando levantar toda sospecha sobre él. El final de la película es el punto de partida del culto a Manuel Rodríguez y la negación del olvido. Pero, insisto, con una vocación conciliatoria y en ningún caso de denuncia o protesta.

Aunque hay otro elemento a considerar. Una de las informaciones de prensa de los días previos al estreno indicaba que "el papel de O'Higgins está representado con toda fidelidad con una caracterización perfecta por el teniente de Ejército señor Federico Siemza Steel quien en esta cinta nos demuestra lo que de él se puede esperar" ${ }^{\prime \prime 38}$. En la versión de El húsar de la muerte a la que he tenido acceso (proveniente de la filmoteca de la Universidad de Chile), esa escena no existe, ni aparece O'Higgins en ningún momento. En definitiva, hay un problema con el documento fílmico. Los periódicos de la época reproducen otras escenas que tampoco se encuentran en la versión analizada de la cinta. Por alguna razón, en determinado momento entre la filmación y la realización de las versiones restauradas, O'Higgins desapareció. Esto puede deberse a tres causas. La primera, una decisión del propio Sienna o de su equipo, que habiendo rodado escenas donde figuraba O'Higgins, decidieron no incluirlas durante la etapa de montaje.

\footnotetext{
${ }^{38}$ El Mercurio, 15 de noviembre de 1925, p. 38. La nota incluye la fotografía de una escena, ausente del film.
} 
De haber sido así, ¿fue por razones técnicas? ¿Por razones artísticas? ¿O debido a motivaciones políticas? Pudo ser una decisión que buscara privilegiar la figura de Rodríguez, para que en el marco de la representación melodramática del pasado vehiculado por la cinta, ningún personaje lo opacara. Pero dado que es un largometraje que lidia con personajes y hechos históricos, ese recorte narrativo es también un recorte historiográfico. Deliberado o no, en la práctica, tiene como consecuencia sacar a O'Higgins de la pantalla.

Las otras dos posibles causas están relacionadas entre sí. La versión actual de la cinta fue reconstruida a partir de distintos fragmentos, montados décadas después. El cineasta Sergio Bravo estuvo a cargo de la operación, supervisado por Sienna. Puede que en este paso, y no antes, $\mathrm{O}^{\prime}$ Higgins se haya perdido. Aunque, de nuevo, por dos posibles motivos. Primero, porque de entre los fragmentos usados para restaurar la película, se hubiesen perdido o destruido los fotogramas de las escenas en que participaba O'higgins. Segundo, porque en esta etapa, que corresponde a un nuevo ejercicio de montaje, el director o su nuevo montajista decidieran quitarlo del film.

Sólo conjeturas. Y estas se vuelven más difíciles de formular si tenemos en cuenta que los diarios, antes del estreno, se felicitaban porque iban a poder "ver reflejadas en la pantalla figuras que nos son queridas", de las cuales "la más descollante, la más heroica y cuyo recuerdo es venerado por todos los chilenos es la del general O’Higgins" ${ }^{\prime \prime 3}$. Se podría desconfiar de esos avances informativos, pensando que finalmente el largometraje no incluyó escenas tales, en atención a que en ninguno de los comentarios que siguieron al estreno se menciona la actuación de Siemza, ni los términos en que se estructuraba su personaje. Tampoco la crítica de años posteriores indica algo sobre esta ausencia o presencia.

Pero a estos efectos, O’Higgins, si bien era -y es- efectivamente objeto de culto, lo era del culto oficial, administrador de la reverencia al poder y a los poderosos. Por tal motivo, social y culturalmente ha tenido una significación opuesta a la de Manuel Rodríguez. Mientras que a fines del siglo XIX algunas organizaciones de trabajadores honraron la memoria de éste, peregrinando anualmente a Til-Til, donde fue asesinado, las dimensiones que adquirió en las manifestaciones de la cultura popular de masas situaron a Rodríguez como un personaje humano, cercano al pueblo; capaz, por ejemplo, de empinar un potrillo de chicha y bailar un pie de cueca en una fonda, lo que nunca se ha visto hacer al tieso y distante $\mathrm{O}^{\prime}$ Higgins. 